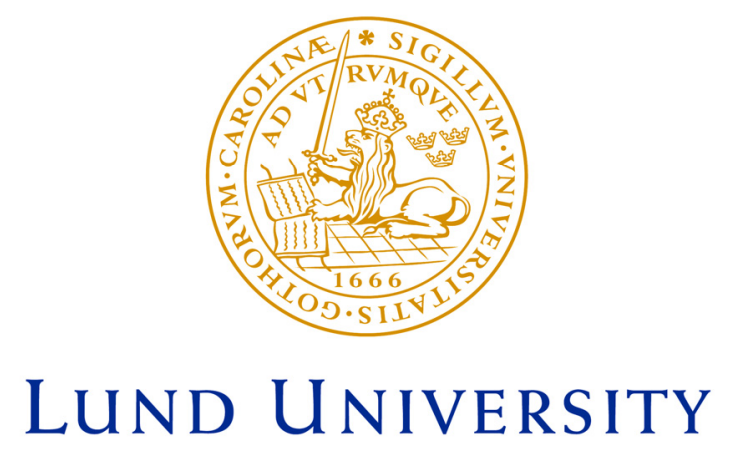

Faculty of Medicine

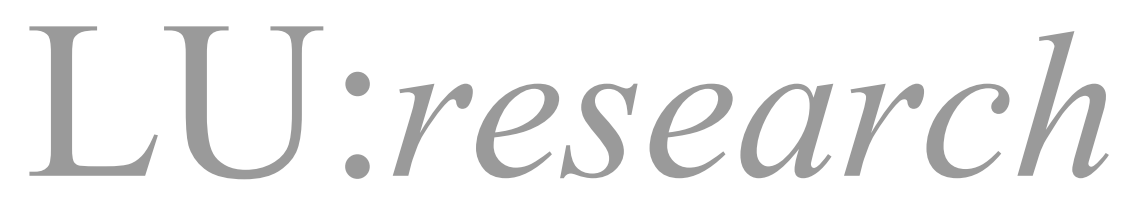

Institutional Repository of Lund University

This is an author produced version of a paper published in Molecular and Cellular Endocrinology. This paper has been peer-reviewed but does not include the final publisher proof-corrections or journal pagination.

Citation for the published paper:

Lundin, K B and Giwercman, A and Dizeyi, N and Giwercman, Y L.

"Functional in vitro characterisation of the androgen receptor GGN polymorphism."

Mol Cell Endocrinol, 2007, Vol: 264, Issue: 1-2, pp. 184-7.

http://dx.doi.org/10.1016/j.mce.2006.11.008

Access to the published version may

require journal subscription.

Published with permission from: Elsevier 


\title{
Functional in vitro characterisation of the androgen receptor GGN polymorphism
}

\author{
KB Lundin ${ }^{1}$, A Giwercman ${ }^{1}$, N Dizeyi ${ }^{2}$ and YL Giwercman ${ }^{1}$ \\ Department of Clinical Sciences, Molecular Reproductive Medicine Research Unit ${ }^{1}$ and \\ Urological Research Unit ${ }^{2}$, Lund University, Malmö, Sweden.
}

\section{Correspondence and reprint requests:}

Yvonne Lundberg Giwercman

CRC, Lund University

Building 91, Plan 10

UMAS, Entrance 72

SE 20502 Malmö, Sweden

Phone no. $+4640391103 \quad$ Fax. +4640391222

E-mail: Yvonne.Giwercman@med.lu.se

Running title: GGN repeat in vitro function

Disclosure statement: None of the authors have anything to declare.

Word count: 2019

The study was supported by grants from The Swedish Research Council (Grant No 521-20046072 and Grant No K2005-72X-14545-03A), The Swedish Cancer Society (Grant No: 4857B05-03XCC) The Swedish Childhood Cancer Society (Grant No RKT04/001and 05/056), Gunnar Nilsson Cancer Fund and Crafoords Foundation. 
Key words: androgen receptor, polymorphism, transcription

\section{Abstract}

Superior androgen receptor (AR) function in subjects carrying a GGN repeat length of 23

(GGN23) has been indicated in vivo. Therefore, the activity of the AR carrying GGN23 combined with CAG22 was compared to the AR with, respectively, GGN10, 24 and 27 combined with CAG22, in the presence of 0.1-100 nM testosterone or DHT. At $100 \mathrm{nM}$ DHT, GGN24 showed 35\% lower transactivating activity (95\% [CI]: 20-50\%) than GGN23. GGN10 and GGN27 also showed significantly less AR activity than GGN23 (mean differences [95\% CI]: $54 \%$ [40-68\%] and 58\% [39-78\%], respectively). The same trend was also observed at lower DHT concentrations. In response to R1881, GGN23 activity was significantly higher than for other lengths.

ARs with other glutamine numbers than 23 have lower transactivating capacity in response to both testosterone and DHT. Congenital malformations and other signs of hypoandrogenism in subjects with AR gene GGN lengths other than 23 could, hence, be related to a lower AR activity. 


\section{Introduction}

Normal androgen action is required for the male sex differentiation of the karyotypic male foetus, development of secondary sex characteristics at puberty and the maintenance of sperm production thereafter (Quigley et al. 1995). Androgen action in the peripheral target cells is mediated via the androgen receptor (AR), which is a nuclear transcription factor, functioning as the main regulator of androgen signalling in the cell. The hormones interacting with the AR are mainly testosterone (T) and $5 \alpha$-dihydrotestosterone (DHT), which both bind to the ligand binding domain of the receptor.

The N-terminal domain, with the transactivating capacity, contains two polymorphic repeats of glutamines and glycines, encoded by $(\mathrm{CAG})_{\mathrm{n}} \mathrm{CAA}$ and $(\mathrm{GGT})_{3} \mathrm{GGG}(\mathrm{GGT})_{2} \mathrm{GGC}_{\mathrm{n}}$, respectively (Lubahn et al. 1989). The latter repeat is generally designated the GGN repeat. The CAG repeat length is normally distributed in the population, spanning from approximately 10-30 repeats, with a median number of 22 in Caucasians (Lundin et al. 2003). An abnormal expansion of the segment to more than 40 repeats has been linked to spinal and bulbar muscular atrophy, also known as Kennedy's disease (La Spada et al. 1991). The CAG repeat has also been suggested to play a role in the pathogenesis of prostate cancer, testicular cancer and male infertility (Giwercman et al. 2004;Irvine et al. 1995; Tut et al. 1997). Experiments in vitro have confirmed the in vivo findings by showing an inverse relationship between the number of CAG repeats and the transactivating capacity of the receptor, with longer CAG stretches resulting in lower AR transactvating capacity than shorter ones. Much less is known regarding the functional role of the GGN repeat. In the general Swedish population the repeat number spans from 10-27 (Lundin, Giwercman, Richthoff, Abrahamsson, \& Giwercman 2003). One predominant allele of 23 (GGN23) has evolved among Caucasians and is carried by $53 \%$ of the Swedish subjects. GGN24, which is the second most common allele, was reported in approximately $32 \%$. However, among patients 
with hypospadias or cryptorchidism the opposite pattern was found, GGN24 or longer being the most frequent genotype, followed by GGN23 (Aschim et al. 2004). In a recent publication on early-onset androgenetic alopecia - male pattern baldness, which is characterized by an androgen dependent defined pattern of hair loss from the scalp, the authors found that GGN23 was associated with the disorder (Hillmer et al. 2005). GGN24 on the other hand, seemed to have a protective effect. These in vivo results indicated that GGN lengths above 23 were associated with lower androgenicity as compared to the most common genotype, GGN23. With respect to GGN lengths shorter than 23, it was recently shown that GGN $<23$ was associated with lower semen volume, as compared to GGN=23 and GGN>23 (Lundin et al. 2006).

Hence, in vivo data have indicated that GGN23 would have a functional advantage (Table 1) and in vitro studies could shed light upon this matter, but to date, there are only two such studies on the GGN repeat. The first study showed that a complete deletion of the GGN polymorphism resulted in a $30 \%$ reduction of the transcriptional activity of the receptor (Gao, Marcelli, \& McPhaul 1996). In the second, more recent study, ARs expressing 19-23 GGN triplets were tested in response to the synthetic testosterone R1881 (Ding et al. 2005). No significant difference in AR transcriptional activity was noted. However, only one concentration of R1881 (10 nM) was tested, and no comparisons were made with the second most common GGN length of 24 repeats, or with extremely short or long GGN repeats. Furthermore, all constructs contained a CAG repeat length of 24 , which is above the average length.

The aim of our study was, therefore, to investigate the transcriptional activity of the androgen receptor carrying the two most common lengths of the GGN repeat, together comprising approximately $85 \%$ of the population, as well as very short (GGN=10) and very long stretches $(\mathrm{GGN}=27)$ in combination with the median $\mathrm{CAG}$ repeat length. 


\section{Methods}

\section{Molecular Cloning}

The CAG repeat was amplified in a $50 \mu \mathrm{PCR}$ reaction containing $0.4 \mu \mathrm{M}$ of each of the primers: AR 4 and AR 1B3' (5'-AGCCTAGCAGGGCAGATCTT-3' and 5'CTGCCTTACACAACTCCTTGGC- 3'), $0.25 \mu \mathrm{M}$ of each dNTP, $1 \times$ Pyrobest II PCR Buffer (Takara Bio Inc., Shiga, Japan), 1.25 U Pyrobest DNA Polymerase (Takara) and approximately $10 \mathrm{ng}$ human leukocyte DNA. Thirty-five cycles of $45 \mathrm{~s}$ denaturation at $96^{\circ} \mathrm{C}$, followed by a 2 min combined annealing and extension step at $72^{\circ} \mathrm{C}$, were performed in an Eppendorf Mastercycler (Eppendorf, Hamburg, Germany), with an initial denaturation step of $3 \mathrm{~min}$ and a final extension step of $5 \mathrm{~min}$. AR fragments containing GGN lengths of 10, 23, 24 or 27 were amplified by PCR from genomic human DNA previously determined to have these lengths as described previously (Lundin, Giwercman, Richthoff, Abrahamsson, \& Giwercman 2003), but with 20 and 25 cycles respectively, for the primary and secondary reactions.

PCR products were digested with Eco52I / BfrI (CAG repeat) or BstEII / KpnI (GGN repeat) (Fermentas Sweden, Helsingborg, Sweden). The resulting products were ligated into a pCMV4 expression vector carrying the full length hAR cDNA, which had been digested with corresponding enzymes. Hence, four constructs were established, carrying 22 CAG repeats and 10, 23, 24 or 27 GGN repeats. The integrity of cloned inserts was verified by direct sequencing on an ABI Prism310 DNA sequencer (PE Corporation, Foster City, CA, USA).

\section{Transient expression of recombinant hAR and trans-activation experiments}

Approximately $10^{6}$ COS- 1 cells (ECACC, Salisbury, UK) were by FuGENE 6 transfection reagent (Roche Diagnostics, Bromma, Sweden) transiently transfected with $0.5 \mu \mathrm{g}$ of the specific pCMV4-AR construct together with $1.5 \mu \mathrm{g}$ of a pGL3-Basic vector harbouring the 
Luciferase reporter gene and the human PSA promoter sequence and $0.1 \mu \mathrm{g}$ of the $\beta$ galactosidase vector pCH110 (Pharmacia, Uppsala, Sweden). After 24 hours of transfection in Dulbecco's Modified Eagle Media (DMEM) (Invitrogen AB, Stockholm, Sweden) containing $10 \%$ foetal bovine serum (Invitrogen) and $0.02 \%$ Gentamicine (Invitrogen) the media was changed to phenol-red free DMEM, containing 10\% dextran-coated charcoal stripped serum and cells were stimulated with increasing concentrations $(0.1-100 \mathrm{nM})$ of the native ligand DHT or the synthetic testosterone R1881. After 24 hours, the cells were harvested and lysed Luciferase and $\beta$-galactosidase activities were measured with the Dual-light assay (Applied Biosystems, Stockholm, Sweden). Protein concentration was assessed by Quick start Bradford protein assay (BioRad, Sundbyberg, Sweden).

As controls, cells were transfected in parallel with pCMV4 without the AR and the CAG22/GGN23 variant was included in all experiments as an internal control. Doublesamples were made for each receptor construct and the experiments were repeated 6 times, with 6 different plasmid preparations.

For each of the two ligands, the activity at $100 \mathrm{nM}$ of hormone with the receptor carrying CAG22/GGN23 was set to $100 \%$. All activities obtained with other constructs and/or hormone concentrations were expressed relative to this.

\section{Western blot analyses}

To ascertain the amount of translated AR in transfected cells, $10 \mu \mathrm{g}$ of proteins from lysed cells were run on a 4-12 \% SDS-PAGE, followed by transfer to PVDF-membrane (Amersham, Pharmacia Biotech, Buckinghamshire, UK). Non-specific binding of proteins was blocked with 5\% non-fat milk in Tris-buffered saline containing $0.2 \%$ Tween 20 (Chemicon, Malmö, Sweden) for $1 \mathrm{~h}$ at $\mathrm{r}$. t. The membranes were probed with a monoclonal antibody against the N-terminal part of the human AR (Dako, Glostrup, Denmark) at a 
concentration of 1:1000, followed by peroxidase-conjugated anti-mouse (1:5000) antibody (Sigma, Saint Louis, Missouri, USA). The proteins were detected by an ECL detection system plus reagent (Amersham). Equal protein loading was verified for all blots by probing for $\beta$ actin (Sigma) expression.

\section{Statistics}

For each ligand concentration, the comparison of transcriptional activity between GGN23 and the three other GGN lengths $(10,24$ and 27) was performed by use of linear regression with GGN length as categorised variable. For all constructs, a mean relative difference in activity, as compared to GGN23, and a 95\% confidence interval (CI) of this difference, was calculated. The difference was statically significant $(p<0.05)$ if the $95 \%$ CI did not encompass $0 \%$. 


\section{Results and discussion}

This is the first in vitro study comparing the transactivating activity of the AR with the two most common GGN alleles in combination with the median CAG length. Current work shows that GGN repeat lengths other than the most frequent length of 23 are associated with lower AR transcriptional activity, both with testosterone and DHT as ligands.

We have recently reported an alteration in the distribution of the GGN lengths among cases with these congenital malformations (Aschim, Nordenskjold, Giwercman, Lundin, Ruhayel, Haugen, Grotmol, \& Giwercman 2004). In these subjects, GGN24 was the most common allele. Thus, we hypothesized, that any increase in GGN length above the most common length of 23 may cause a slight impairment in AR function, which, combined with insufficient Leydig cell function and/or increased exposure to environmentally derived anti-androgens, may lead to undervirilisation of male genital organs.

The experiments in the present study support the previously reported in vivo findings, with the receptor containing 23 glycines (GGN23) being superior in function compared to all other lengths tested. The receptor harbouring 24 glycines (GGN24) had (mean difference [95\% CI] $35 \%$ [20-50\%] lower transactivating capacity than GGN23 at $100 \mathrm{nM}$ DHT (Figure 1). Shorter (GGN10) and longer GGN tracts (GGN27) also showed significantly less AR activity than GGN23 (mean differences [95\% CI]: $54 \%$ [40-68\%] and 58\% [39-78\%], respectively). The same trend, with better GGN23 function compared to the other tested lengths, was observed also at lower concentrations. However, statistical significance was only noted with respect to GGN27, which had a 45\% [8.5-82\%] lower activity than GGN23 at $10 \mathrm{nM}$ DHT and $92 \%$ [16-100\%] at $1 \mathrm{nM} \mathrm{DHT.} \mathrm{Other} \mathrm{lengths} \mathrm{did} \mathrm{not} \mathrm{differ} \mathrm{statistically} \mathrm{from} \mathrm{each} \mathrm{other,}$ although GGN24 had the highest transactivating ability, followed by GGN10 and GGN27. 
In response to the synthetic testosterone R1881, the activity of the AR expressing GGN23 was high at all concentrations tested and differed statistically significantly in activity from all the other tested lengths (Figure 2).

Thus, compared to GGN23, GGN24 gave 68\% [52-84\%], 49\% [25-73\%], 44\% [18-70\%] and $61 \%$ [34-90\%] lower activity at 100nM, $10 \mathrm{nM}, 1 \mathrm{nM}$ and $0.1 \mathrm{nM}$, respectively. The corresponding mean differences [95\% CI] were 64\% [52-84\%], 75\% [49-100\%], 44\% [16$73 \%$ ] and 59\% [28-90\%] for GGN10 and 44\% [28-59\%], 59\% [37-81\%], 63\% [38-87\%] and $63 \%$ [35-88\%] for GGN27. The results from Western blots revealed that the differences in AR function were not caused by an increased expression of AR protein in the cells transfected with GGN23 (Figure 3).

In the present study, PSA, which is a physiological target gene for androgen action and in particular associated with prostate function, was used as a marker of AR gene transcriptional activity. The choice of PSA may play a role for the obtained results and could be an explanation for the necessity of high DHT levels in order to see a strong AR activity. It might well be, that other results had been obtained at lower DHT levels by using other promoters. Our findings are in parallel with those reported by other groups. In a recent study on a number of compounds (among them R1881 and DHT), R1881 was found to be the most potent in binding. It was also most potent in driving a reporter gene, regardless of which promoter that was used, whereas DHT generated the same pattern as in our study, with low activity at concentrations below $10 \mathrm{nM}$. The results were also depending on the cell type (Simon \& Mueller 2006). The differences of the androgenic potencies of R1881 compared to the natural androgen DHT in COS-1 cells, as used in our work, might also be due to distinct co-activator expression and conformational changes of the liganded AR induced by the natural androgen. In conclusion, our results show that there is no linear relationship between the AR transactivating capacity and the length of the GGN repeat as has previously been shown for 
the CAG repeat. ARs with other GGN repeat lengths than the most common one of 23 , have lower transactivating capacity, in response to both testosterone (R1881) and DHT, paralleling the frequency of this repeat in most, if not all, Caucasian populations studied to date (Lundin, Giwercman, Richthoff, Abrahamsson, \& Giwercman 2003;Macke et al. 1993). 


\section{Acknowledgements}

We wish to thank Åke Lundwall and Yvonne Olsson for kindly providing us with the vector harbouring the PSA promoter together with the Luciferase reporter gene, and Margareta Persson for valuable technical assistance. 


\section{Legends to figures}

\section{Figure 1.}

Comparison of transcriptional activity between ARs carrying CAG22 in combination with:

$23,24,10$ or 27 GGN repeats, in response to DHT. The activity for each construct is shown relative to the activity of the GGN23 variant.

\section{Figure 2.}

Comparison of transcriptional activity between ARs carrying CAG22 and 23, 24, 10 or 27 GGN repeats, in response to R1881. The activity for each construct is shown relative to the activity of the GGN23 variant.

\section{Figure 3.}

Western blot showing AR protein expression in transiently transfected COS-1 cells. Lane 1-4 represent 10, 23, 24, and $27 \mathrm{GGN}$, respectively, in response to $100 \mathrm{nM}$ DHT, whereas lane 58 display the same constructs in response to $100 \mathrm{nM}$ R1881. The left panel shows samples from 3 experiments pooled together, whereas the right panel shows samples from one experiment. 


\section{References}

Aschim, E. L., Nordenskjold, A., Giwercman, A., Lundin, K. B., Ruhayel, Y., Haugen, T. B., Grotmol, T., \& Giwercman, Y. L. 2004, "Linkage between Cryptorchidism, Hypospadias, and GGN Repeat Length in the Androgen Receptor Gene", J.Clin.Endocrinol.Metab, vol. 89, no. 10, pp. 5105-5109.

Ding, D., Xu, L., Menon, M., Prem Veer Reddy, G., \& Barrack, E. R. 2005, "Effect of GGC (glycine) repeat length polymorphism in the human androgen receptor on androgen action", The Prostate, vol. 62, pp. 133-139.

Gao, T., Marcelli, M., \& McPhaul, M. J. 1996, "Transcriptional activation and transient expression of the human androgen receptor", J Steroid Biochem Mol Biol, vol. 59, pp. 9-20.

Giwercman, A., Lundin, K. B., Eberhard, J., Stahl, O., Cwikiel, M., Cavallin-Stahl, E., \& Giwercman, Y. L. 2004, "Linkage between androgen receptor gene CAG trinucleotide repeat length and testicular germ cell cancer histological type and clinical stage", European Journal of Cancer, vol. 40, no. 14, pp. 2152-2158.

Hillmer, A. M., Hanneken, S., Ritzmann, S., Becker, T., Freudenberg, J., Brockschmidt, F. F., Flaquer, A., Freudenberg-Hua, Y., Jamra, R. A., Metzen, C., Heyn, U., Schweiger, N., Betz, R. C., Blaumeiser, B., Hampe, J., Schreiber, S., Schulze, T. G., Hennies, H. C., Schumacher, J., Propping, P., Ruzicka, T., Cichon, S., Wienker, T. F., Kruse, R., \& Nothen, M. M. 2005, "Genetic variation in the human androgen receptor gene is the major determinant of common early-onset androgenetic alopecia", Am J Hum Genet, vol. 77, pp. 140-148.

Irvine, R. A., Yu, M. C., Ross, R. K., \& Coetzee, G. A. 1995, "The CAG and GGC microsatellites of the androgen receptor gene are in linkage disequilibrium in men with prostate cancer", Cancer Research, vol. 55, pp. 1937-1940.

La Spada, A. R., Wilson, E. M., Lubahn, D. B., Harding, A. E., \& Fischbeck, K. H. 1991, "Androgen receptor gene mutations in X-linked spinal and bulbar muscular atrophy", Nature, vol. 352, pp. 77-79.

Lubahn, D. B., Tan, J.-A., Quarmby, V. E., Sar, M., Joseph, D. R., French, F. S., \& Wilson, E. M. 1989, "Structural analysis of the human and rat androgen receptors and expression in male reproductive tract tissues", Annals of the New York Academy of Sciences, vol. 564, pp. 48-56.

Lundin, K. B., Giwercman, Y. L., Rylander, L., Hagmar, L., \& Giwercman, A. 2006, "Androgen receptor gene $G G N$ repeat length and reproductive characteristics in young Swedish men", European Journal of Endocrinology, vol. 155, pp. 347-354.

Lundin, K. B., Giwercman, A., Richthoff, J., Abrahamsson, P.-A., \& Giwercman, Y. L. 2003, "No association between mutations in the human androgen receptor GGN repeat and inter-sex conditions", Mol.Hum.Reprod., vol. 9, no. 7, pp. 375-379.

Macke, J. P., Hu, N., Hu, S., Bailey, M., King, V. L., Brown, T., Hamer, D., \& Nathans, J. 1993, "Sequence variation in the androgen receptor gene is not a common determinant of male sexual orientation", Am J Hum Genet, vol. 53, pp. 844-852. 
Quigley, C. A., De Bellis, A., Marschke, K. B., El-Awady, M. K., Wilson, E. M., \& French, F. S. 1995, "Androgen receptor defects: historical, clinical, and molecular perspectives", Endocrine Reviews, vol. 16, pp. 271-321.

Simon, S. \& Mueller, S. O. 2006, "Human reporter gene assays: transcriptional activity of the androgen receptor is modulated by the cellular environment and promoter context", Toxicology, vol. 220, pp. 90-103.

Tut, T. G., Ghadessy, F. J., Trifiro, M. A., Pinsky, L., \& Young, E. L. 1997, "Long polyglutamine tracts in the androgen receptor are associated with reduced trans-activation, impaired sperm production, and male infertility", JCEM, vol. 82, pp. 3777-3782. 


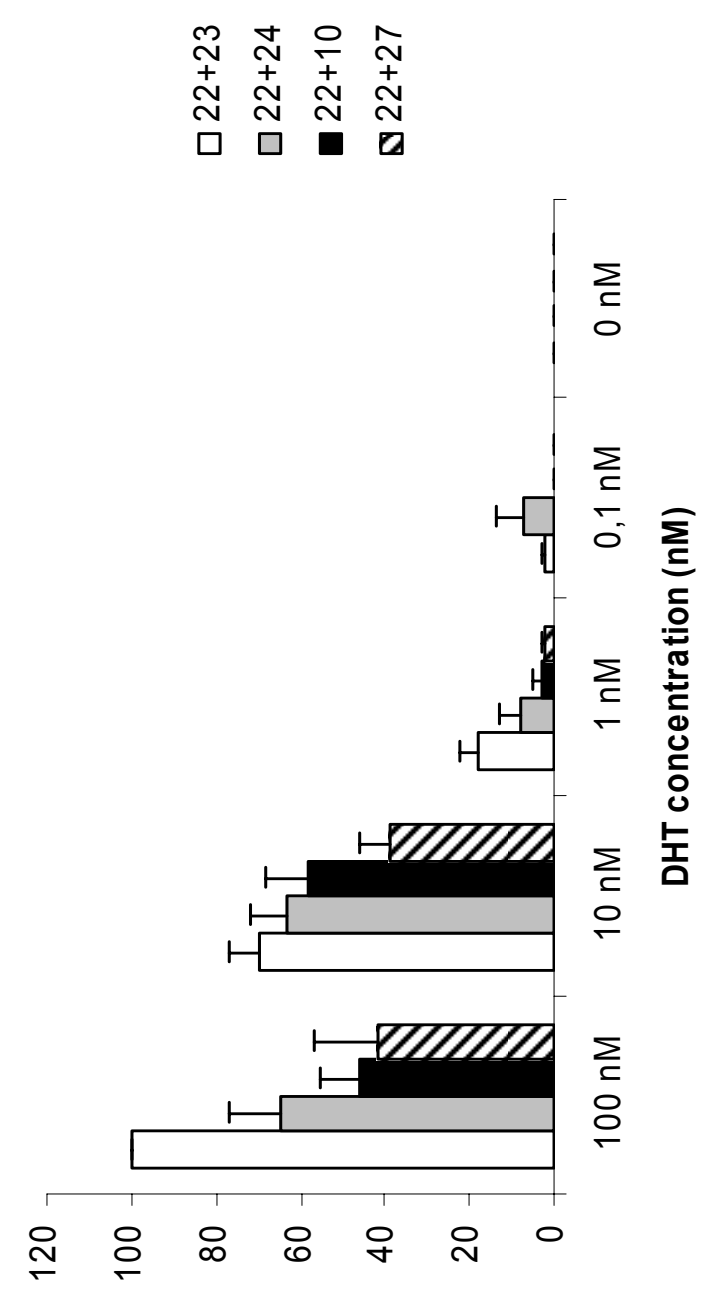

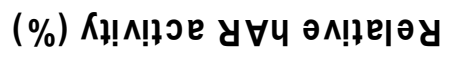

矛 


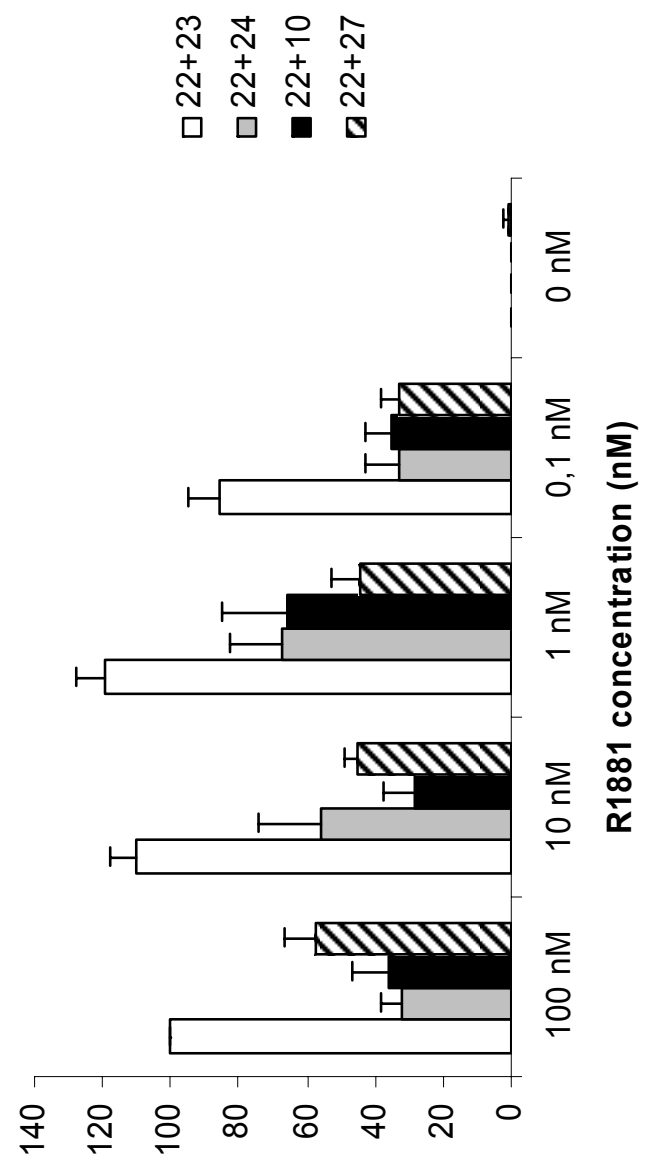

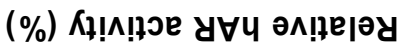

Do 


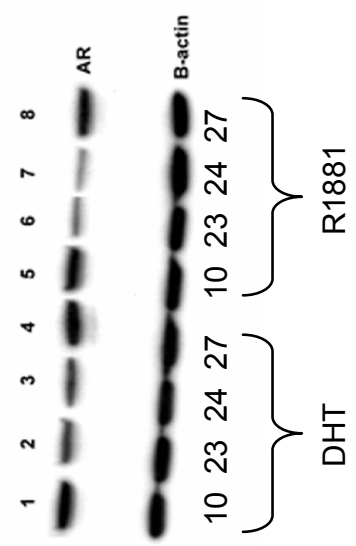

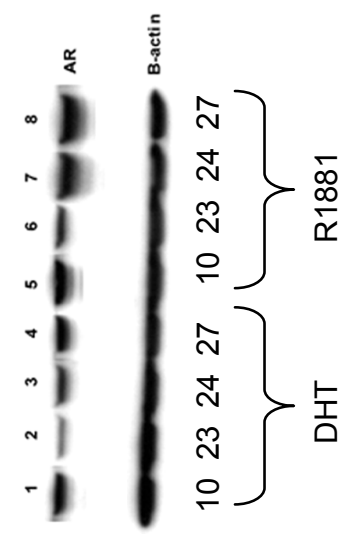

赵 


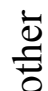

웅

胥

0

4

해용

(9)

Z

.

空

छ

$\stackrel{2}{ \pm}$

$\frac{\sqrt{0}}{3}$

.

$\stackrel{2}{3}$

.

$\stackrel{\Xi}{\Xi}$

.

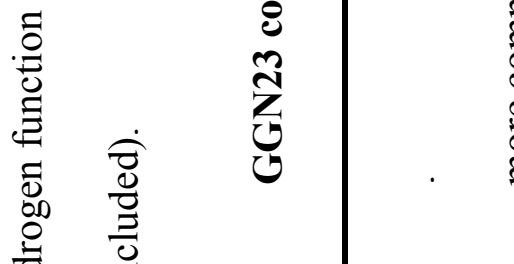

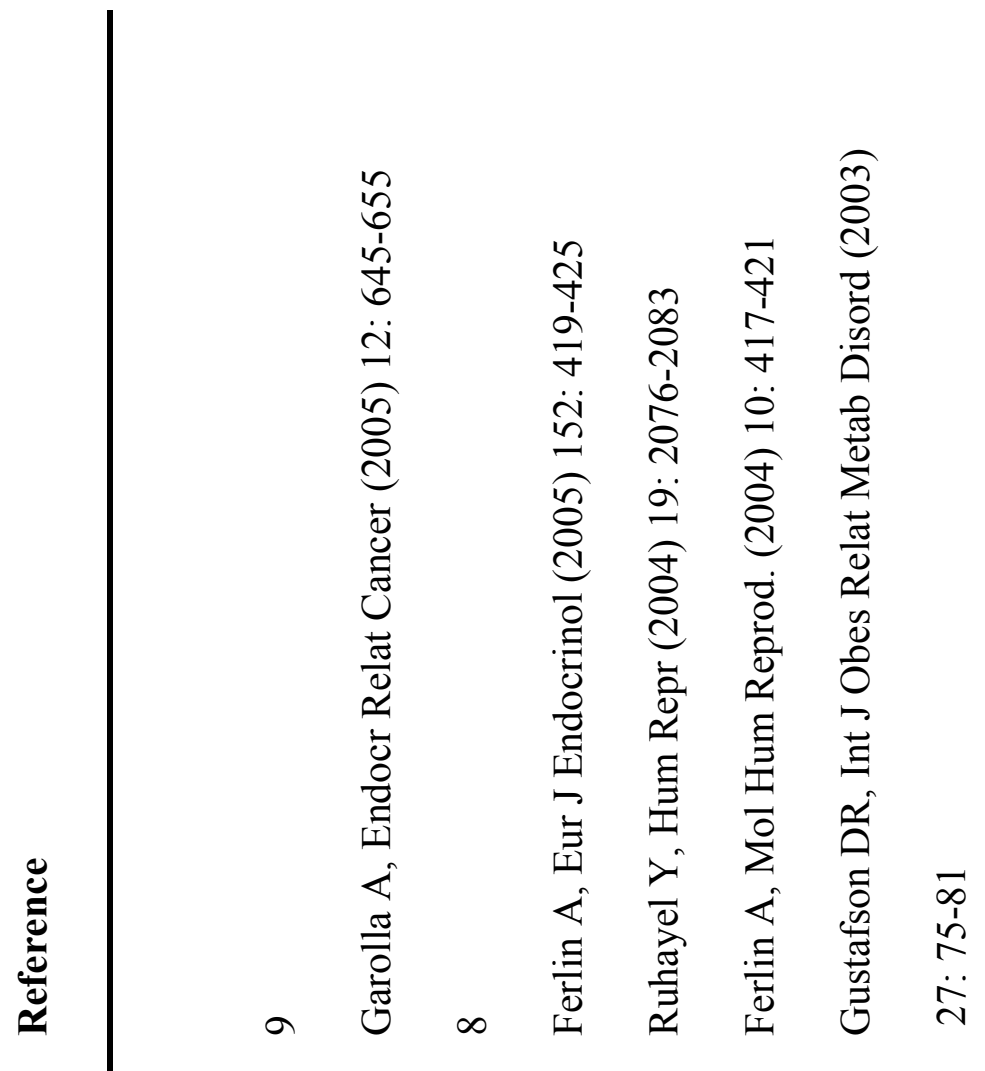

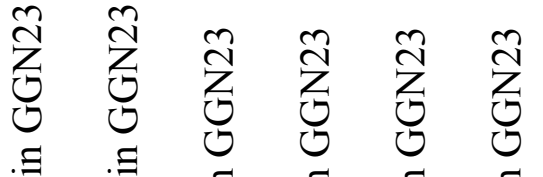

. $\quad . \quad . \Xi \quad . \Xi \quad . \Xi \quad \Xi$

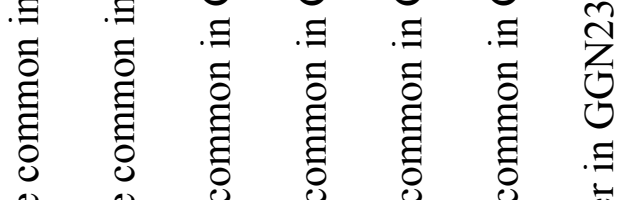

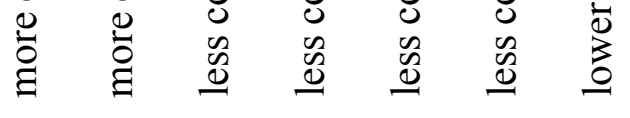

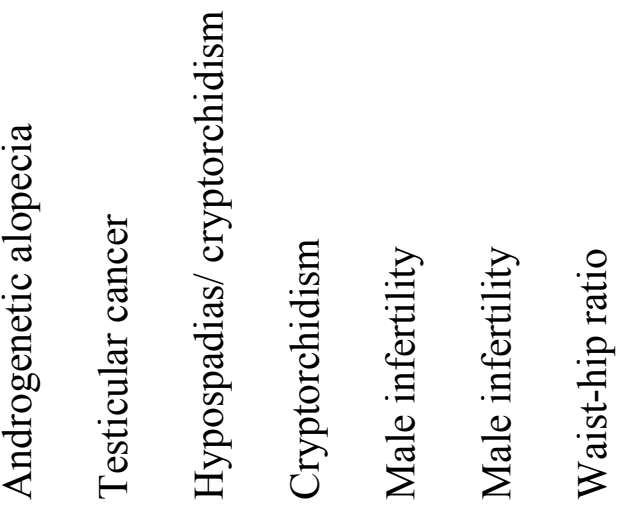

